\title{
Aerosol effects on the cloud optical depth retrieval from atmospheric transmittance
}

Josep-Abel González, and Josep Calbó

Citation: AIP Conference Proceedings 1531, 556 (2013); doi: 10.1063/1.4804830

View online: https://doi.org/10.1063/1.4804830

View Table of Contents: http://aip.scitation.org/toc/apc/1531/1

Published by the American Institute of Physics

\section{Articles you may be interested in}

Aerosol-cloud interactions $(\mathrm{ACl})$ viewed by satellite and ground-based remote sensing

AIP Conference Proceedings 1531, 464 (2013); 10.1063/1.4804807

Estimation of cloud optical depth for low clouds from UV erythemal irradiance

AIP Conference Proceedings 1531, 895 (2013); 10.1063/1.4804915

Py4CAtS - Python tools for line-by-line modelling of infrared atmospheric radiative transfer

AIP Conference Proceedings 1531, 123 (2013); 10.1063/1.4804723

Ground-based aerosol optical depth inter-comparison campaigns at European EUSAAR super-sites AIP Conference Proceedings 1531, 584 (2013); 10.1063/1.4804837

Comparison between measurements and model simulations of solar radiation at a high altitude site: Case studies for the Izana BSRN station

AIP Conference Proceedings 1531, 864 (2013); 10.1063/1.4804907

Aerosols in forecasts of the UV index: A comparison of different approaches

AIP Conference Proceedings 1531, 772 (2013); 10.1063/1.4804884

\section{Conference Proceedings}

\section{Get $30 \%$ off all print proceedings!}

Enter Promotion Code PDF-30 at checkout 


\title{
Aerosol Effects on the Cloud Optical Depth Retrieval from Atmospheric Transmittance
}

\author{
Josep-Abel González and Josep Calbó \\ Physics Department, University of Girona, Escola Politècnica Superior, 17071 Girona, Spain
}

\begin{abstract}
Among the cloud properties, cloud optical depth is particularly useful to describe the cloud, and can be determined from surface measurements of the total atmospheric transmittance in some shortwave bands. Here we use a very simple two-stream treatment of the radiative transfer to show how cloud optical depth determinations could be affected by various aerosol properties. Results show how, in connection with the fact that cloud drops and aerosol particles have different optical properties, the aerosol optical depth has an effect considerably higher than it could be expected. Likewise, the effect of the aerosol properties and the ground albedo on the cloud optical depth determination is addressed. The results are compared with simulations performed with a more rigorous (but still one-dimensional) radiative transfer code. It is found that the two-stream method considered can roughly reproduce the results obtained using more rigorous treatments. The general conclusion is that aerosol optical properties have a remarkable effect and thus they must be taken into account when retrieving cloud optical properties.
\end{abstract}

Keywords: Aerosol, Aerosol optical depth, Cloud optical depth, Atmospheric transmittance.

PACS: 92.60.H, 92.60.Mt

\section{INTRODUCTION}

Optical characterization of clouds is of interest for climatic studies. Among the cloud properties, cloud optical depth (COD) is particularly useful to describe the cloud, and can be determined from surface measurements of the total atmospheric transmittance in some shortwave bands. Various methods have been proposed which take into account or not the effect of the aerosol load of the atmosphere on the cloud optical depth determination [1-3]. Here we use a very simple two-stream treatment of the radiative transfer to show how COD determinations are affected by various aerosol properties: the aerosol optical depth (AOD), the single scattering albedo (SSA) and the asymmetry parameter $(\mathrm{g})$. With this aim, the total transmittance is calculated for conditions with both cloud and aerosol, and then the method is inverted to obtain an estimation of COD assuming that no aerosol is present. Furthermore, a more rigorous radiative transfer model is also used to confirm the importance of considering the aerosol load and properties when determining COD.

\section{THE TWO-STREAM TREATMENT}

Here, the two-stream formulation for a mono-directional radiation field is used [4]. The cloud is considered an optically thick non-absorbing medium (layer 1 ) with asymmetry parameter $g_{1}$, whereas the aerosol layer, which can absorb radiation, is considered optically thin (layer 2). Moreover, aerosol is considered entirely laying between the cloud and the ground, which is reflective. The transmittance and reflectance of the cloud having optical depth COD are [4]:

$$
\begin{aligned}
& T_{1}=\frac{2}{2+\left(1-g_{1}\right) C O D} \\
& R_{1}=\frac{C O D}{2+\left(1-g_{1}\right) C O D}
\end{aligned}
$$


For the aerosol layer with optical depth AOD, single scattering albedo $\omega_{2}$ and asymmetry parameter $g_{2}$, the transmittance and reflectance are expressed:

$$
\begin{gathered}
T_{2}=\exp (-A O D)+[1-\exp (-A O D)] \omega_{2} \frac{1+g_{2}}{2} \\
R_{2}=[1-\exp (-A O D)] \omega_{2} \frac{1-g_{2}}{2}
\end{gathered}
$$

The combined total transmittance $T_{12+\text { surf }}$ can be obtained from the individual transmittances $T_{1}$ and $T_{2}$, the reflectances $R_{l}$ and $R_{2}$, and the ground reflectivity $R_{s}$ :

$$
\begin{gathered}
T_{12}=\frac{T_{1} T_{2}}{1-R_{1} R_{2}} \\
R_{12}=R_{2}+\frac{R_{1} T_{2}^{2}}{1-R_{1} R_{2}} \\
T_{12+\text { surf }}=\frac{T_{12}}{1-R_{12} R_{s}},
\end{gathered}
$$

where $T_{12}$ and $R_{12}$ are respectively the combined transmittance and reflectance of the layers. This two stream formulation can be easily inverted to obtain the COD from the combined total transmittance, provided the aerosol parameters are given.

To assess the aerosol effect on the COD determination the total transmittance has been calculated for conditions with both cloud and aerosol, and then the method is inverted to obtain an estimation of COD assuming that no aerosol is present. The overestimation in the COD determination depends upon the aerosol optical depth (AOD), its single scattering albedo (SSA) $\omega_{2}$, the asymmetry parameter $g_{2}$, the surface reflectivity $R_{s}$ and the cloud optical depth (COD) itself. The asymmetry parameter for the cloud droplets has been fixed to $g_{l}=0.85$, corresponding to a wavelength of $415 \mathrm{~nm}$ and a droplet effective radius around $8 \mu \mathrm{m}$. For the aerosol layer both single scattering albedo $\omega_{2}$ and asymmetry parameter $g_{2}$ are considered variables depending upon the aerosol constituents and particle size distribution aerosol.

Calculations show how, in connection with the fact that cloud droplets and aerosol particles have different optical properties, the AOD has an effect considerably higher than it could be expected. For example, for an actual COD of 20 combined with an AOD of only 0.2 , and a surface reflectivity of 0.04 , the retrieved COD by inversion of the treatment is 20.75 , corresponding to a relative error introduced of about $4 \%$. Thus for these conditions AOD has an effect 4 times its value. This amplification factor increases both with COD, AOD and the surface reflectivity, reaching values well above 4 . Relative error decreases with COD, reaching values close to $1 \%$ for very thick clouds, whereas it increases with AOD (Figure 1a).
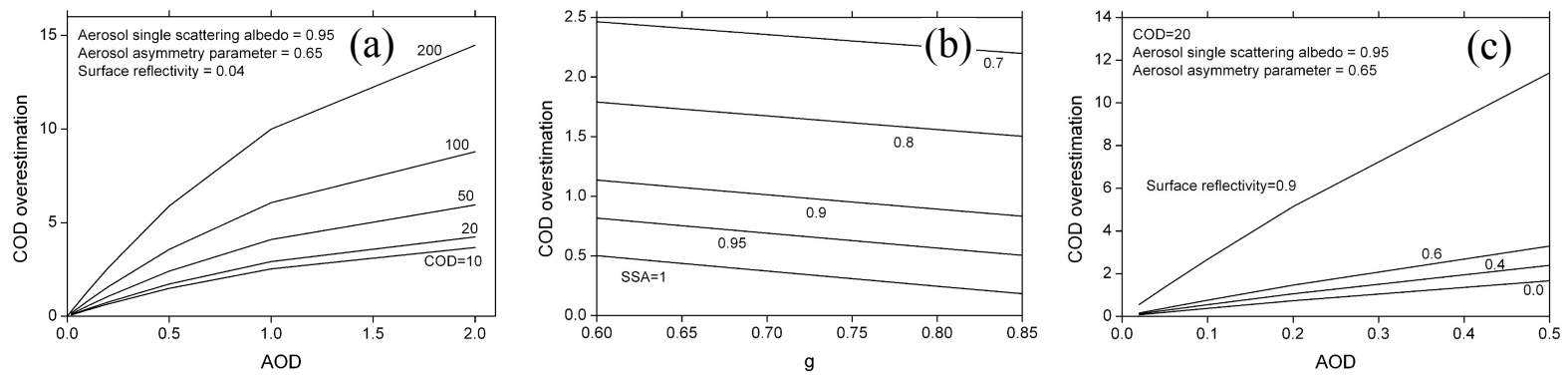

FIGURE 1. (a) Cloud optical depth overestimation depending on AOD and COD. (b) Cloud optical depth overestimation depending on the aerosol properties SSA and g. (c) Combined effect of AOD and surface reflectivity in the COD determination.

Besides its dependence on COD and AOD, the retrieval errors (and thus the amplification factor) are also affected by other aerosol properties as SSA and $\mathrm{g}$. Both the relative error in the retrieval and the amplification factor 
decrease when SSA or $g$ increase. Thus, the COD overestimation increases for absorbing and small particles (Figure 1b). High surface reflectivity can also contribute to considerable overestimation in the COD retrieval (Figure 1c). For a non-reflective bottom surface, AOD effect is still remarkable (for $\mathrm{COD}=20$ and $\mathrm{AOD}=0.2$, retrieved COD is 20.73).

\section{RESULTS OBTAINED WITH A RIGOROUS RADIATIVE TRANSFER CODE}

A more rigorous (but still one-dimensional) atmospheric radiative transfer code, SBDART [5], has been also used to confirm the importance of taking into account the aerosol effects. The analysis is done considering a horizontally homogeneous single layer cloud above an aerosol layer, for the $415 \mathrm{~nm}$ wavelength, corresponding to the first channel of the Multifilter Rotating Shadowband Radiometer (MFRSR). In Table 1 the values of some parameters adjusted in the model are shown. In the example, $\mathrm{COD}=20$ and $\mathrm{AOD}=0.2$ were introduced in the model to obtain the total atmospheric transmittance. Then aerosol was removed $(\mathrm{AOD}=0)$ and $\mathrm{COD}$ was adjusted to obtain the same value of the total transmittance. The new value of COD is considered the "retrieved COD".

TABLE (1). Reference conditions used in SBDART.

\begin{tabular}{ll}
\hline Solar zenith angle & $0 \mathrm{deg}$ \\
Ground albedo & 0.04 \\
Droplet effective radius & $8 \mu \mathrm{m}$ \\
COD at $550 \mathrm{~nm}$ & 20 \\
COD at $415 \mathrm{~nm}$ & 19.82 \\
AOD at $415 \mathrm{~nm}$ & 0.2 \\
Aerosol SSA & 0.95 \\
Aerosol g & 0.65
\end{tabular}

For the reference case a COD of 21.16 must be introduced to obtain the same transmittance when aerosol is present, for the sun in the zenith. For a solar zenith angle of $60^{\circ}$, the COD must be 21.30 . These values correspond to errors of $5.8 \%$ and $6.5 \%$ respectively. Effects of other parameters on the retrieval are also addressed and shown in Table 2. As can be seen in Table 2, the overestimation in COD is much higher than the value of AOD. The amplification is defined here as the ratio between the overestimation in COD and the value of AOD.

TABLE (2). Results for conditions varied with respect the reference.

\begin{tabular}{clccccc}
\hline & & \multicolumn{2}{c}{ Retrieved COD } & Overestimation & Amplification \\
\hline & & @ $550 \mathrm{~nm}$ & @ $415 \mathrm{~nm}$ & & & \\
Reference & & 21.16 & 20.97 & 1.2 & $5.8 \%$ & 5.8 \\
Conditions & $\mathrm{SZA}=60 \mathrm{deg}$ & 21.30 & 21.11 & 1.3 & $6.5 \%$ & 6.5 \\
changed with & $\mathrm{SSA}=0.7$ & 24.50 & 24.28 & 4.5 & $22.3 \%$ & 22.3 \\
respect the & $\mathrm{g}=0.85$ & 25.60 & 25.38 & 5.6 & $27.8 \%$ & 27.8 \\
reference & Ground albedo $=0.8$ & 24.10 & 23.89 & 4.1 & $20.3 \%$ & 20.3
\end{tabular}

\section{APPLICATION TO 1-YEAR DATABASE}

Data from the SGP site of ARM (36 $\left.36^{\circ} 18^{\prime \prime} \mathrm{N}, 97^{\circ} 29^{\prime} 6^{\prime \prime} \mathrm{W}\right)$, corresponding to overcast conditions (determined by a Total Sky Imager) from 116 days along 2006 have been used to show the aerosol effect as calculated with the two-stream treatment (19,325 1-min data). Monthly mean aerosol optical depth was taken from AERONET. MFRSR takes measurements of the global and diffuse shortwave irradiance at some narrow bands: 415, 500, 615, 673, 870 and $940 \mathrm{~nm}$. Only the $415 \mathrm{~nm}$ band is used here. In Figure 2 the distribution and the evolution of the estimated COD is shown, besides the overestimation caused by the neglected contribution of the aerosol. The mean (median) of the amplification for this database is around 5 (4.4). 


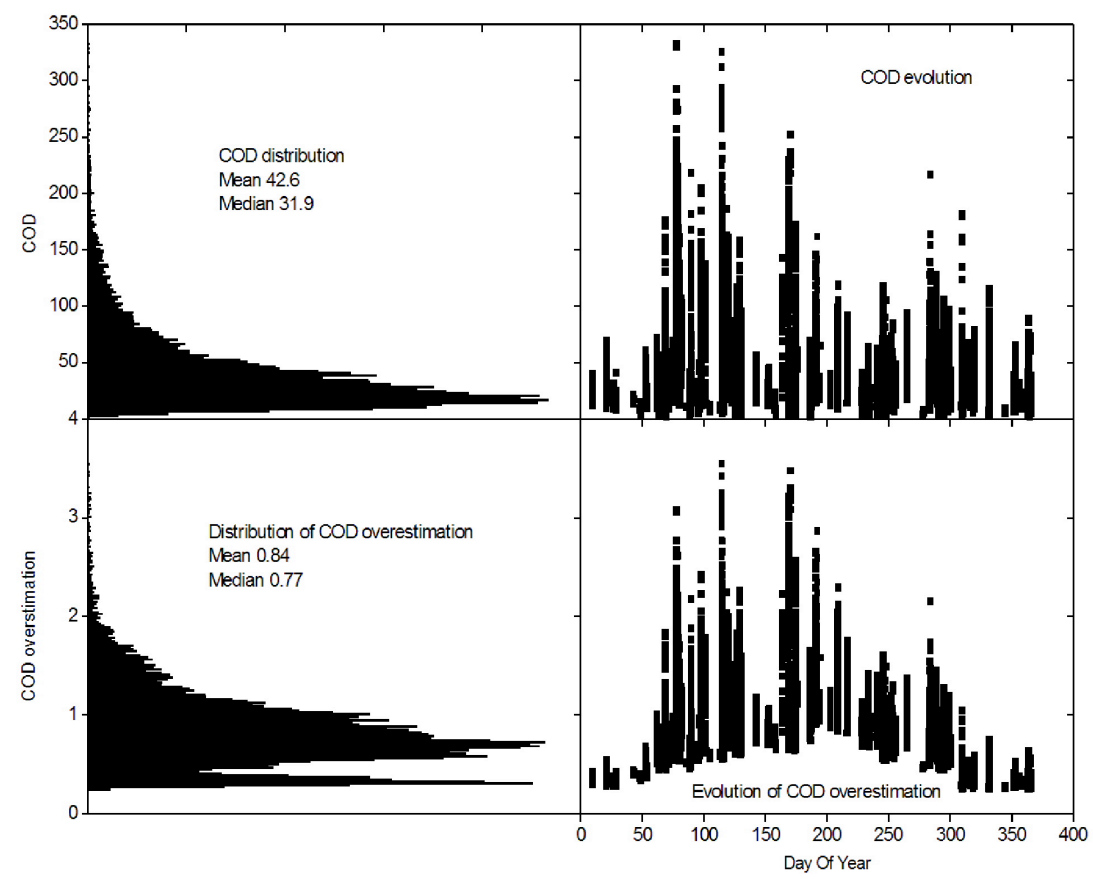

FIGURE 2. Distribution and evolution of the COD and its overestimation caused by the neglected contribution of AOD.

\section{CONCLUDING REMARKS}

It has been found that the two-stream method considered can roughly reproduce the results obtained using more rigorous treatments. A simple application of the method to a 1-year database taken from the ARM facilities at SGP site has been performed showing the effect of AOD on the COD retrieval.

The general conclusion is that aerosol optical properties have a remarkable effect and thus they must be taken into account when retrieving cloud optical properties.

\section{ACKNOWLEDGMENTS}

Data were obtained from the Atmospheric Radiation Measurement (ARM) Program sponsored by the U.S. Department of Energy, Office of Science, Office of Biological and Enviromental Research, Climate and Environmental Sciences Division. The Cimel Sun-Photometer measurements of aerosol optical depth were collected by the U.S. Department of Energy as part of the Atmospheric Radiation Measurement Program Climate Research Facility (ACRF) and processed by the National Aeronautics and Space Administration's Aerosol Robotic Network (AERONET). We thank Rick Wagener for its effort in establishing and maintaining AERONET Cart_Site data. This study has been funded by the Spanish Ministry of Science and Innovation, through project NUCLIERSOL (MICINN, CGL2010-18546).

\section{REFERENCES}

1. Q. Min and L. C. Harrison, J. Geophys. Res. 101(D1), 1635-1640 (1996).

2. Q. Min and L. C. Harrison, Geophys. Res. Lett. 23(13), 1641-1644 (1996).

3. S. Matamoros, J. A. González and J. Calbó, J. Appl. Met. Clim. 50(2), 283-295 (2011).

4. C. F. Bohren, Am. J. Phys. 55(6), 524-533 (1987).

5. P. Ricchiazzi, S. Yang, C. Gautier and D. Sowle, Bull. Amer. Meteor. Soc. 79, 2101-2114 (1998). 